\title{
KIRCHGÄSSNER, Bernhard, BECHT, Hans-Peter, Vom Städtebund zum Zweckverband. 30. Arbeitstagung in Waiblingen, 1991
}

Joseph Morsel

\section{(2) OpenEdition}

\section{Journals}

Édition électronique

URL : http://journals.openedition.org/ifha/1888

DOI : $10.4000 /$ ifha. 1888

ISSN : 2198-8943

Éditeur

IFRA - Institut franco-allemand (sciences historiques et sociales)

Référence électronique

Joseph Morsel, « KIRCHGÄSSNER, Bernhard, BECHT, Hans-Peter, Vom Städtebund zum Zweckverband 30. Arbeitstagung in Waiblingen, 1997 », Revue de I'IFHA [En ligne], Date de recension, mis en ligne le 01 janvier 1995, consulté le 22 septembre 2020. URL : http://journals.openedition.org/ifha/1888 ; DOI : https://doi.org/10.4000/ifha. 1888

Ce document a été généré automatiquement le 22 septembre 2020.

(CIFHA 


\title{
KIRCHGÄSSNER, Bernhard, BECHT, Hans-Peter, Vom Städtebund zum Zweckverband. 30. Arbeitstagung in Waiblingen, 1991
}

\author{
Joseph Morsel
}

1 Du Moyen Age central jusqu'à nos jours, des villes ont cherché à résoudre dans l'alliance ou l'association des problèmes ou des défis qui excédaient la force d'une communauté urbaine isolée. Ces problèmes pouvaient être propres au fonctionnement urbain et à son emprise sur le plat-pays (problèmes d'approvisionnement, de sécurité intérieure, de circulation) ou alors d'ordre socio-politique (essentiellement l'affirmation face aux forces sociales en place). Les alliances ou associations qui en ont découlé pouvaient faire cause commune avec le pouvoir local, ou alors s'opposer précisément à lui. La fin du Moyen Age est caractéristiquement l'âge des ligues, qu'elles soient nobiliaires ou urbaines, obéissant fondamentalement au principe du bien commun: propter communem utilitatem, comme le déclare une charte de 1277 par laquelle les quatre villes westphaliennes de Dortmund, Münster, Soest et Osnabrück concluent un accord défensif, qui a constitué par la suite une référence constante dans le cadre des ligues plus ou moins étendues et dont le but proclamé est toujours le maintien ou la restauration de la paix. L'étude de J.K.W.B., qui s'étend du milieu du XIIIe au milieu du XVe s., est un exemple caractéristique de l'histoire institutionnelle que pratiquent certains historiens d'Outre-Rhin, alignant une série de traités qui fait en définitive apparaître comme une évolution linéaire le passage des premières ligues (1246 et 1253) à l'organisation du canton hanséatique des villes westphaliennes (achevée vers 1430), l'accord de 1277 ayant servi de cadre essentiel à la genèse du canton. Une perspective étroite.

2 Alors que les ligues westphaliennes envisagées groupaient des villes territoriales (donc soumises à des princes laïcs ou ecclésiastiques), l'étude d'E.H. concerne les villes libres et impériales, en particulier du Sud de l'Empire (où elles présentent la plus forte 
densité), engagées dans le bras de fer entre les princes et Venceslas. Celui-ci a adopté une attitude différente de celle de son père (elle-même rappelée de manière détaillée) vis-à-vis des villes, en raison de la plus grande fragilité de sa position politique et de ses besoins d'ordre financiers: les villes représentaient pour cela une source de revenus et un appui politique; par ailleurs, les villes libres et impériales étaient elles-mêmes intéressées par l'appui que le roi des Romains pouvait leur apporter face à la puissance princière (notamment du point de vue de leur autonomie judiciaire). Le règne de Venceslas se caractérise ainsi par de multiples phases de rapprochement où chacune des parties trouvait son compte (par exemple lors des transferts aux villes des créances des Juifs), et notamment par le soutien de Venceslas aux ligues urbaines, en particulier dans le cadre de la Guerre des Villes (1388-1389). Le rapprochement épisodique ne s'est toutefois jamais mué en alliance constante, en raison de réserves des deux côtés - sans compter la grande hétérogénéité du parti urbain, où les villes franconiennes et de la Wetterau étaient proches, les villes alsaciennes ouvertes, mais les villes souabes plutôt distantes du roi -, ce qui a laissé en définitive Venceslas démuni lorsque les princes électeurs l'ont déposé en 1400.

3 L'ouvrage dirigé par B.K. et H.-P.B. aborde le problème de l'association interurbaine dans un cadre plus large. Face à ce dépassement, aujourd'hui de plus en plus nécessaire d'un point de vue général (social, économique, culturel, politique, etc.) du cadre urbain, une première contribution pose, dans une perspective de géographie territoriale la question d'un avenir de la ville et de l'histoire urbaine. Suit une étude de l'une des associations les plus célèbres et durables de l'histoire urbaine: la Décapole alsacienne, suivie depuis sa fondation en 1354 sous les auspices impériaux et à des fins de paix territoriale, jusqu'à sa destruction de fait sur ordre de Louis XIV au moment de l'occupation de l'Alsace durant la Guerre de Hollande. Le déclin des formes d'organisation supra-urbaine à la suite de la Guerre de Trente Ans apparait également dans le cas du collège des villes impériales à la Diète d'Empire permanente, où les villes ruinées et soumises à la pression princière ont perdu le rôle qui était le leur au XVIe s. L'étude de la formation du système des partis dans le grand-duché de Bade entre 1819 et 1933 montre l'opposition fondamentale entre les villes, dont la bourgeoisie s'engage dans le libéralisme à la fois économique et politique, et les campagnes, qui fournissent les forces du parti catholique - un contraste villes/campagnes que la NSDAP sera le premier parti à dépasser. Face au pouvoir impérial restauré dans l'Allemagne wilhelminienne, les oligarchies urbaines, conscientes de leur poids lourd économique et de leur poids plume politique, ont tenté d'acquérir une force parallèle par le biais des associations, qui ont pris la forme, à la fin du XIXe s., d'assemblées urbaines (Städtetage), remplacées au début du XXe s. par des conférences de maires (Bürgermeisterkonferenzen), toutes formes d'association qui ont eu à faire face à des problèmes divers d'ordre urbanistique (infrastructures et équipements collectifs, urbanisme) et sociaux (notamment pendant et après la Première Guerre mondiale). Une dernière contribution est consacrée à la genèse, aux objectifs et à l'importance de l'Association des villes de Bade-Wurtemberg, dont les premiers linéaments apparaissent dès les lendemains de la capitulation et dont l'activité est organisée par la réunion d'assemblées urbaines (Städtetage). 